\title{
Austenite Grain Growth Kinetics in API X65 and X70 Line-Pipe Steels during Isothermal Heating
}

\author{
Asiful Hossain Seikh, ${ }^{1}$ Mahmoud S. Soliman, ${ }^{2}$ Abdulhakim AlMajid, ${ }^{1,2}$ \\ Khaled Alhajeri, ${ }^{3}$ and Waleed Alshalfan ${ }^{3}$ \\ ${ }^{1}$ Centre of Excellence for Research in Engineering Materials, Advanced Manufacturing Institute, King Saud University, \\ P.O. Box 800, Riyadh 11421, Saudi Arabia \\ ${ }^{2}$ Mechanical Engineering Department, College of Engineering, King Saud University, P.O. Box 800, Riyadh 11421, Saudi Arabia \\ ${ }^{3}$ SABIC Technology Center, Saudi Basic Industries Corporation, Jubail, Saudi Arabia
}

Correspondence should be addressed to Mahmoud S. Soliman; solimanm@ksu.edu.sa

Received 20 January 2014; Revised 17 March 2014; Accepted 31 March 2014; Published 17 April 2014

Academic Editor: Shuichi Miyazaki

\begin{abstract}
Copyright (C) 2014 Asiful Hossain Seikh et al. This is an open access article distributed under the Creative Commons Attribution License, which permits unrestricted use, distribution, and reproduction in any medium, provided the original work is properly cited.

The aim of the present work is to investigate the microstructural behavior of austenite grain size (AGS) during the reheating process of two different API steel grades (X65 and X70). The steel samples were austenitized at $1150^{\circ} \mathrm{C}, 1200^{\circ} \mathrm{C}$, and $1250^{\circ} \mathrm{C}$ for various holding times from 10 to 60 minutes and quenched in ice water. The samples were then annealed at $500^{\circ} \mathrm{C}$ for 24 hours to reveal the prior AGS using optical microscopy. It was noticed that the AGS in X65 grade is coarser than that of X70 grade. Additionally, the grain size increases with increasing the reheating temperature and time for both steels. The kinetics of grain growth was studied using the equation $\left(d^{n}-d_{0}{ }^{n}\right)=\operatorname{Atexp}(-Q / R T)$, where $d$ is the measured grain size, $d_{o}$ is the initial grain size, $n$ is the grain size exponent, $t$ is the heating time, $T$ is the heating temperature, $Q$ is the activation energy, $R$ is the gas constant, and $A$ is a constant. To characterize the grain growth process the values of $n, Q$, and $A$ were determined. Good agreement is obtained between the prediction of the model and the experimental grain size values.
\end{abstract}

\section{Introduction}

Steel pipelines are considered the most economical transportation method of the crude oil and gas at present. In recent years, big reservoirs of oil and gas are almost located in environmentally severe regions far from major markets. Meanwhile, the long-distance pipelines must inevitably face severe working conditions, such as earthquake, landslide, and debris flow. The main modifications of the pipeline steel concerns are to have excellent combination of strength and toughness, high deformability, weldability, and resistance to embrittlement related to hydrogen [1-5].

In such context, the application of API 5L grade pipes such as $\mathrm{X}-65$ and $\mathrm{X}-70$, which is considered as high-strength low alloy (HSLA) steels, is presented as a potential solution to enhance the reliability in the operation of these pipes in hostile environments and consequently the attendance of almost strict details posted in the steel procurement specifications.

HSLA steels, with low carbon content $<0.1 \mathrm{wt} . \%$, have an outstanding performance as compared to conventional $\mathrm{C}-\mathrm{Mn}$ steels, due to their better combination of strength and toughness. The mechanical properties were enhanced as a result of using microalloying elements $(\mathrm{Ti}, \mathrm{Nb}, \mathrm{V}, \mathrm{Mo}$, and $\mathrm{Ni}$ ) in addition to the controlled thermomechanical processing [5-7]. The microalloying elements improve the strength properties due to fine precipitation within the grains in addition to the pinning effect in the hardenability of the steels leading to grain refinement.

Reheating temperature prior to the rolling of the steel is one of the important parameters to assure the uniformity and control of the coarsening of austenitic microstructure. The reheating temperature has a great influence on the austenite grain size, precipitation dissolution degree, and 


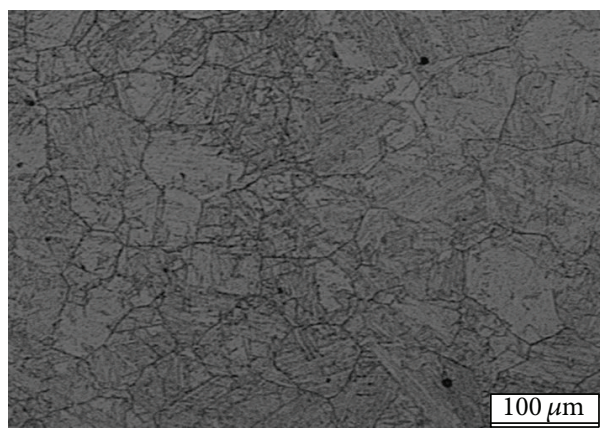

$1150^{\circ} \mathrm{C} / 10 \min (d=48.33 \mu \mathrm{m})$

(a)

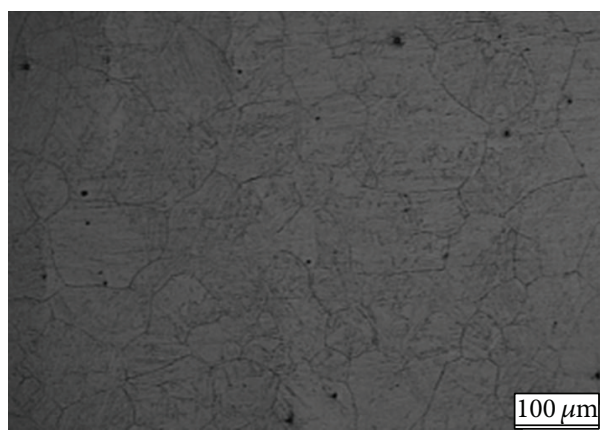

$1200^{\circ} \mathrm{C} / 10 \min (d=61.37 \mu \mathrm{m})$

(c)

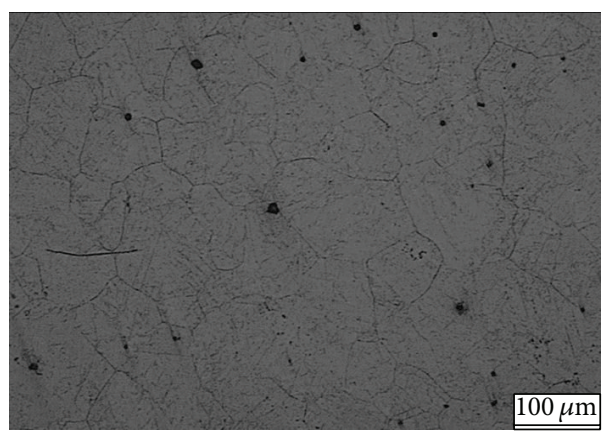

$1250^{\circ} \mathrm{C} / 10 \min (d=69.34 \mu \mathrm{m})$

(e)

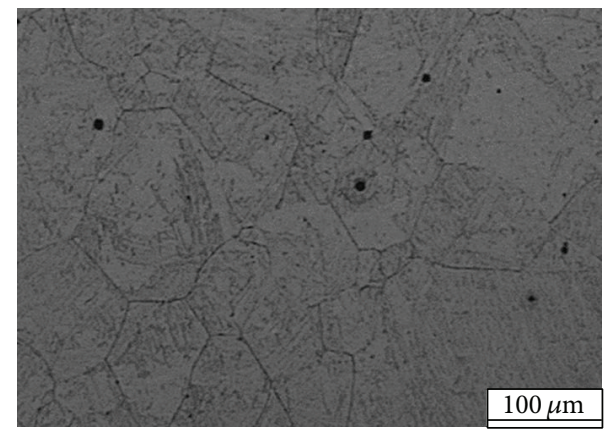

$1150^{\circ} \mathrm{C} / 60 \min (d=82.00 \mu \mathrm{m})$

(b)

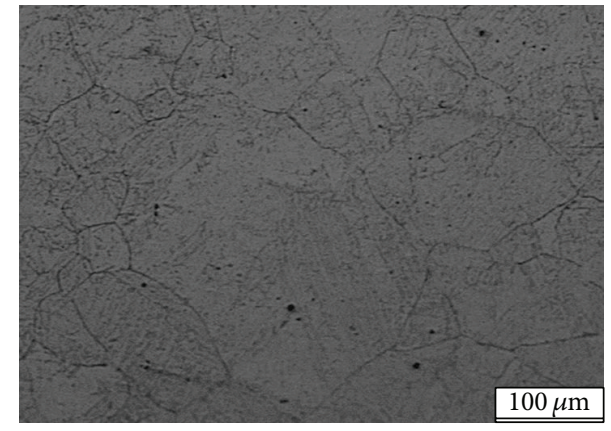

$1200^{\circ} \mathrm{C} / 60 \min (d=95.31 \mu \mathrm{m})$

(d)

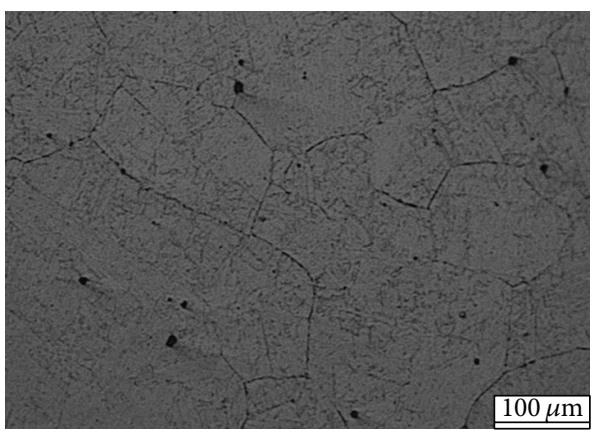

$1250^{\circ} \mathrm{C} / 60 \min (d=98.54 \mu \mathrm{m})$

(f)

Figure 1: Microstructure micrographs of X65 grade after being heat treated at three temperatures $\left(1150^{\circ} \mathrm{C}, 1200^{\circ} \mathrm{C}\right.$, and $\left.1250^{\circ} \mathrm{C}\right)$ and holding times (10 min. and $60 \mathrm{~min}$.).

austenite stabilization. Hence, it is essential to know the required reheating temperature to dissolve the microalloying carbides, nitrides, and carbonitrides. Guaranteed uniformity and control of the coarsening can be achieved by delaying austenite grain growth during the reheating process prior to the hot rolling. Delay effects are made by nonsoluble particles of carbides, nitrides, or carbonitrides which show a strong pinning effect to grain boundary. These particles lose their function of delaying grain growth whereby they enter to solid solution after exceeding the specific dissolution temperature $[8,9]$. The strong influence of temperature on the grain size can be interpreted as a measure for dissolution of $\mathrm{Nb}$ and $\mathrm{V}$ carbonitrides [10]. TiN is more effective in pinning the microstructure than $\mathrm{Nb}$ and $\mathrm{V}$ carbides. TiN particles dissolve at higher temperatures as compared to the other particles [11]; nitrides are substantially less soluble than the corresponding carbides. The next parameter to ensure the uniformity and control the coarsening of austenite microstructure is the time, which has a weak effect $[8,9]$. The difference in precipitates population develops upon solidification, but reheating to temperatures higher than $1250^{\circ} \mathrm{C}$ causes complete dissolution of the precipitates and leads to removing of all particle pinning [12-14]. Conventional reheating in hot strip and plate mills is usually carried out at lower temperatures, between $1150^{\circ} \mathrm{C}$ and $1250^{\circ} \mathrm{C}$ for HSLA steels $[13,14]$. 


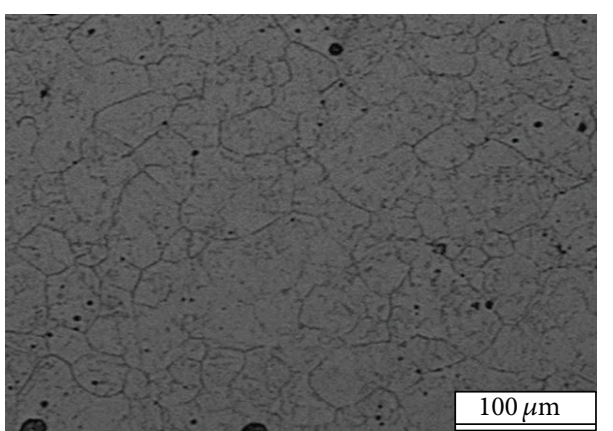

$1150^{\circ} \mathrm{C} / 10 \min (d=36.18 \mu \mathrm{m})$

(a)

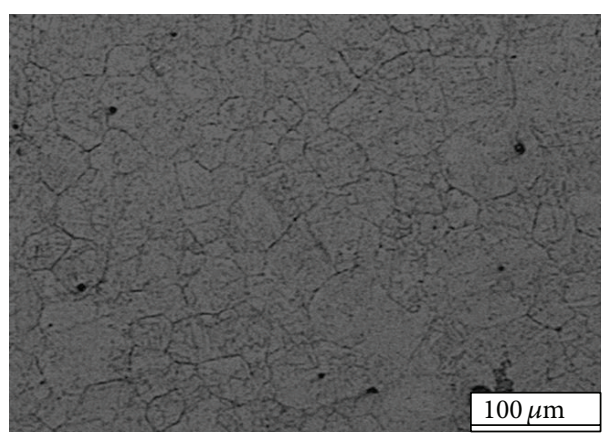

$1200^{\circ} \mathrm{C} / 10 \min -20 \mathrm{x}(d=41.58 \mu \mathrm{m})$

(c)

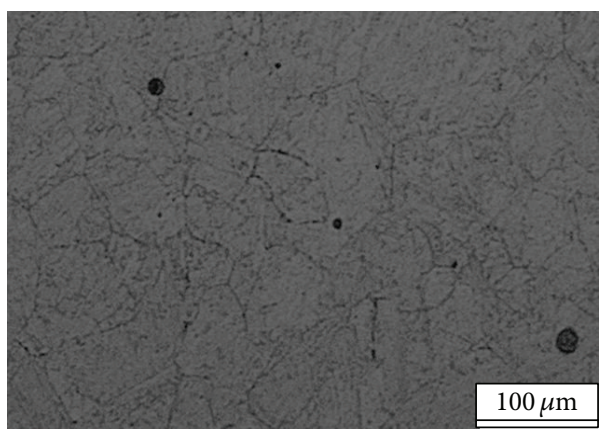

$1250^{\circ} \mathrm{C} / 10 \min (d=52.03 \mu \mathrm{m})$

(e)

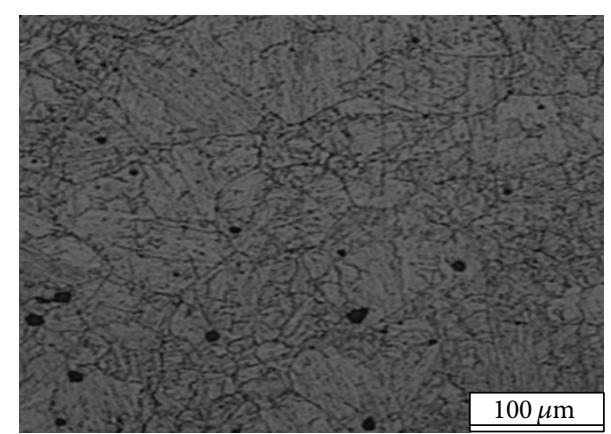

$1150^{\circ} \mathrm{C} / 60 \min (d=56.12 \mu \mathrm{m})$

(b)

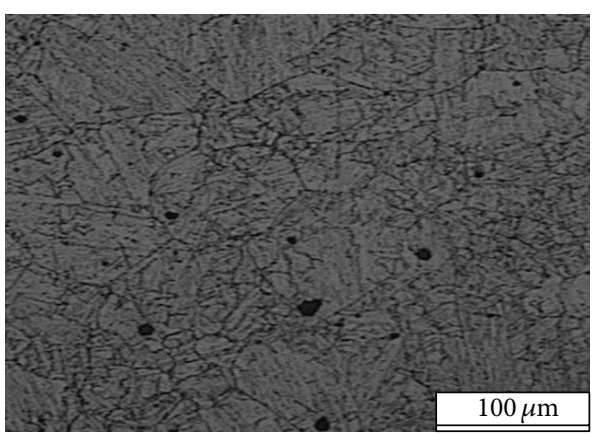

$1200^{\circ} \mathrm{C} / 60 \min -20 \mathrm{x}(d=62.24 \mu \mathrm{m})$

(d)

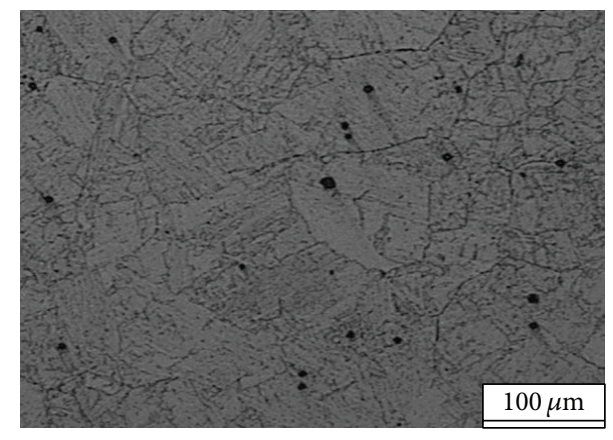

$1250^{\circ} \mathrm{C} / 60 \min (d=73.93 \mu \mathrm{m})$

(f)

FIGURE 2: Microstructure micrographs X70 grade after being heat treated at three temperatures $\left(1150^{\circ} \mathrm{C}, 1200^{\circ} \mathrm{C}\right.$, and $\left.1250^{\circ} \mathrm{C}\right)$ and holding times (10 min. and $60 \mathrm{~min}$.).

In the present work, the effect of austenitizing temperature and heating time on the kinetics of grain growth in two API steel grades (X65 and X70) will be thoroughly investigated.

\section{Materials and Experimental Work}

The materials used for this experimental work were API steel grades X65 and X70 with the chemical composition shown in Table 1 . The steels were supplied by SABIC in the form of hotrolled plate of $15 \mathrm{~mm}$ thickness. Specimens with dimensions of $20 \mathrm{~mm} \times 10 \mathrm{~mm} \times 10 \mathrm{~mm}$ were cut from the plate by diamond blade under coolant at low speed of $300 \mathrm{rpm}$. It is worth mentioning, as shown in Table 1, that the amount of $\mathrm{Ti}$ and $\mathrm{N}$ and their ratio are different in both steels. The effect of this difference in chemical composition will be further discussed in detail. The amount of V in X70 is much lower than that in X65. Also, X65 does not contain Mo while X70 has almost $0.2 \%$ of Mo.

2.1. The Reheating Cycle. To determine the effect of reheating temperature and soaking time on the austenite grain size, samples were reheated at $1150^{\circ} \mathrm{C}, 1200^{\circ} \mathrm{C}$, and $1250^{\circ} \mathrm{C}$ in a high temperature heating furnace (Nobertherm) equipped with an inert gas station. Five samples were soaked at the required temperature for $10,20,30,45$, and 60 minutes and 


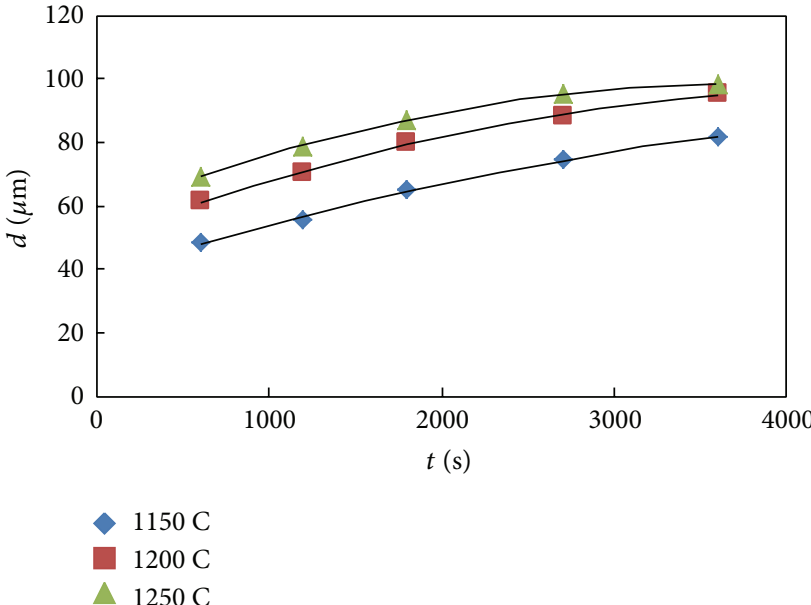

(a)

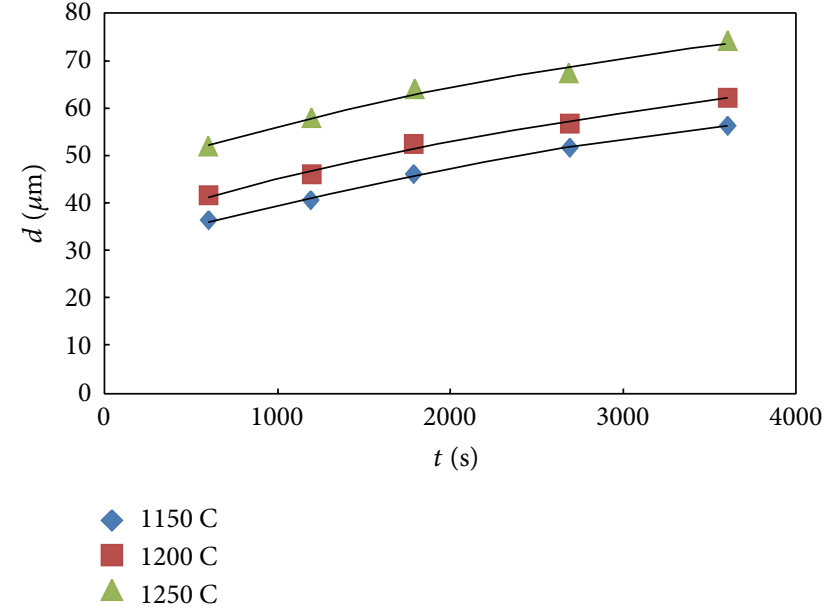

(b)

Figure 3: Grain size $(d, \mu \mathrm{m})$ versus holding time $(t, \mathrm{sec})$ plot of (a) X65 grade and (b) X70 grade.

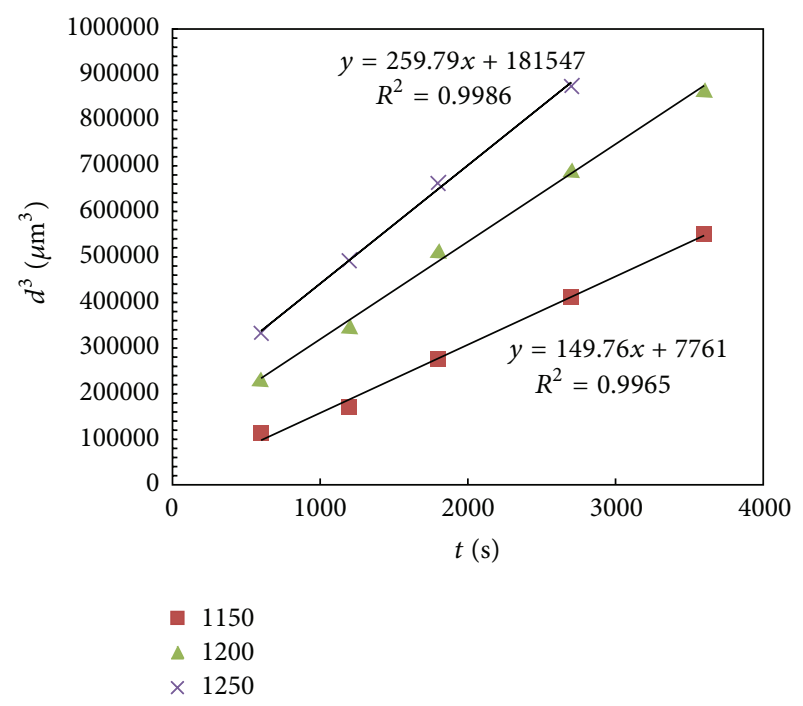

(a)

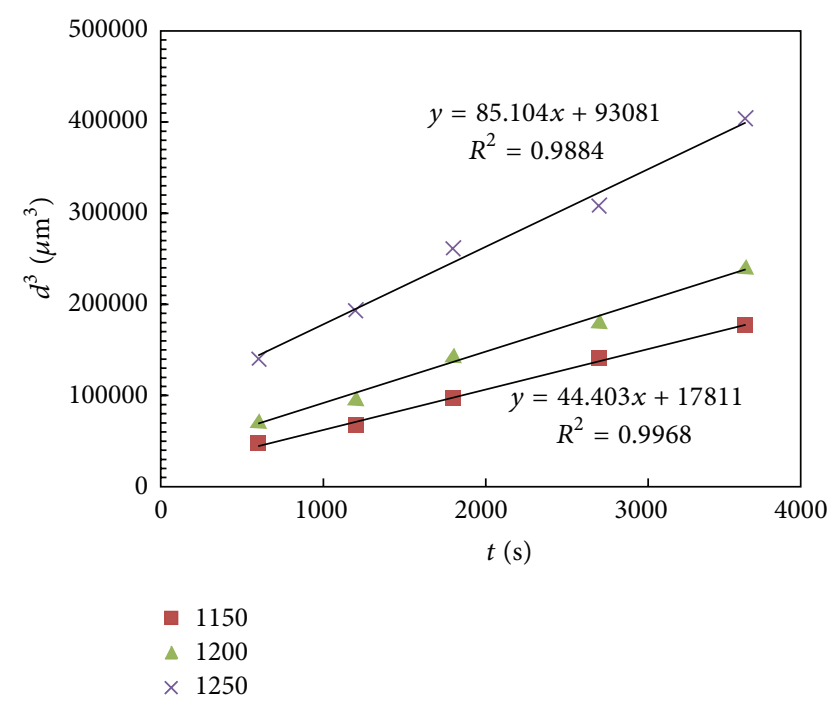

(b)

FIgURE 4: $d^{3}$ versus $t$ plot for (a) X65 and (b) X70.

subsequently quenched in ice water. Sample heating was conducted in nitrogen gas atmosphere flowing at rate of $350 \mathrm{~mL} / \mathrm{min}$. to minimize the oxidation of the samples. After quenching and to get prominent austenite grain boundary, all the samples were soaked at $500^{\circ} \mathrm{C}$ in $\mathrm{N}_{2}$ gas atmosphere for $24 \mathrm{hrs}$ to allow for impurity atoms to diffuse to grain boundaries to be delineated in the etching process.

2.2. Grain Size Measurement. Samples were prepared for metallographic analysis and etched in a mixed solution of saturated aqueous solution of picric acid $(10 \mathrm{~mL}$ picric acid with $2 \mathrm{~mL} \mathrm{H}_{2} \mathrm{O}$ ). The solution was kept at $50-55^{\circ} \mathrm{C}$, with an etching time about $120 \mathrm{~s}$. The microstructure was examined by optical microscopy equipped with image analyzer.
The average diameter of austenite grains was measured using the linear intercept method.

\section{Results and Discussion}

3.1. Metallographic Examination. The microstructures of prior austenite grain size, as a function of heating time and temperature, are shown in Figures 1 and 2 for the X65 and X70 grades, respectively, and the values of grain size measurements in $\mu \mathrm{m}$ are given in Table 2 for both grades, respectively. From Table 2, it is seen that the austenite grain size in X65 steel is larger than that of X70 steel. Also the grain size increases with the increase in holding time and temperature for both steels. 
TABLE 1: Chemical composition of API steel grades X65 and X70.

\begin{tabular}{lccccccccccccc}
\hline Steel & $\mathrm{C}$ & $\mathrm{Si}$ & $\mathrm{Mn}$ & $\mathrm{P}$ & $\mathrm{S}$ & $\mathrm{Al}$ & $\mathrm{Ti}$ & $\mathrm{Cu}$ & $\mathrm{Cr}$ & $\mathrm{Mo}$ & $\mathrm{Nb}+\mathrm{V}$ & $\mathrm{Ni}$ & $\mathrm{N}$ \\
\hline $\mathrm{X} 65$ & 0.08 & 0.25 & 1.5 & 0.01 & 0.002 & 0.05 & 0.02 & 0.003 & 0.016 & - & $<0.12$ & - & 0.005 \\
$\mathrm{X} 70$ & 0.05 & 0.25 & 1.5 & 0.01 & 0.002 & 0.04 & 0.018 & 0.05 & 0.014 & 0.2 & $<0.09$ & 0.02 & 0.0064 \\
\hline
\end{tabular}

TABLE 2: Grain size $(d, \mu \mathrm{m})$ of X65 and X70 grades with reheating time.

\begin{tabular}{|c|c|c|c|c|c|c|}
\hline \multirow{3}{*}{ Holding time, $s$} & \multicolumn{6}{|c|}{ Reheating temperature ${ }^{\circ} \mathrm{C}$} \\
\hline & \multicolumn{2}{|c|}{$1150^{\circ} \mathrm{C}$} & \multicolumn{2}{|c|}{$1200^{\circ} \mathrm{C}$} & \multicolumn{2}{|c|}{$1250^{\circ} \mathrm{C}$} \\
\hline & $\mathrm{X} 65$ & $\mathrm{X} 70$ & X65 & $\mathrm{X} 70$ & X65 & $\mathrm{X} 70$ \\
\hline 600 & 48.33 & 36.18 & 61.37 & 41.58 & 69.34 & 52.03 \\
\hline 1200 & 55.39 & 40.62 & 70.26 & 45.88 & 78.90 & 57.84 \\
\hline 1800 & 65.06 & 45.92 & 80.03 & 52.43 & 87.16 & 63.94 \\
\hline 2700 & 74.4 & 52.01 & 88.35 & 56.59 & 95.69 & 67.54 \\
\hline 3600 & 82 & 56.12 & 95.31 & 62.24 & 98.54 & 73.93 \\
\hline
\end{tabular}

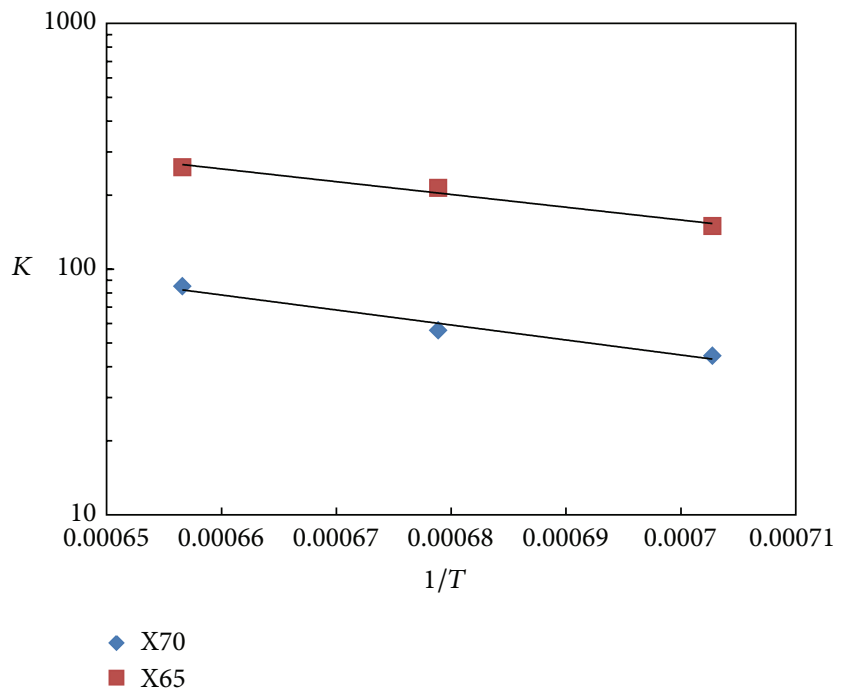

Figure 5: $K$ versus 1/T plot for X65 and X70 steels.

Figures 3(a) and 3(b) show the effect of heating time and temperature on grain growth in X65 and X70, respectively.

3.2. Grain Size Kinetics. The kinetics of isothermal grain growth has been known to obey the following classical relationship [15]:

$$
d^{n}-d_{o}^{n}=K t
$$

where $d$ is the mean grain diameter, $d_{o}$ is the initial grain size at $t=0, n$ is the grain size exponent that depends on the material, and $K$ is a rate constant that depends on temperature. The elementary theories of grain growth predict a value of 2 for $n$ for very pure metals or at high temperatures [15]. The rate constant Kcan be expressed by the Arrhenius equation $[16,17]$ as follows:

$$
K=A \exp \left(-\frac{Q}{R T}\right)
$$

where $Q$ is the activation energy for the grain growth, $A$ is a constant that is assumed to be independent of the temperature and time, $R$ is the universal gas constant, and $T$ is the absolute temperature. Combining (1) and (2), the relation between grain size, time, and temperature can be written as Arrhenius type equation of the form

$$
d^{n}-d_{o}^{n}=A t \exp \left(-\frac{Q}{R T}\right)
$$

To characterize the grain growth process, the values of $n$, $Q$ and $A$ have to be determined from the measurements of austenite grain size at different reheating temperatures and times. Equation (1) usually used to calculate the value of $n$ by simply assuming that $d_{o}$ is much smaller than $d$ and that (1) is reduced to $d=k^{\prime} t^{m}$, where $m$ is equal to $1 / n$. While this assumption can be justified in case of pure metals and solid solution alloys at high temperatures [15], it was questioned in case of microalloyed steels because $d_{o}$ is usually in the order of $d$ values [18], which is the case in present investigation. To solve this difficulty, (1) can be differentiated to have a relation for isothermal rate of grain growth of the form

$$
\dot{d}=\left(\frac{K}{n}\right) d^{(1-n)}
$$

The value of $n$ at various temperatures was estimated from a correlation based on (4) and the experimental data presented in Figure 3 for both steels. An average value of $n \sim 3$ is taken for both steels. To examine the validity of such estimate $(n=3)$ for both steels, $d^{3}$ is plotted versus $t$ using linear scale in Figures 4(a) and 4(b) for X65 and X70, respectively. It is seen from the figure that good correlation is obtained with a regression factor $R^{2}$ that is close to 0.99 . Such a plot is very important because it can be used to find the values of $K$ and $d_{o}{ }^{3}$ at various temperatures. These values can be used to determine the activation energy for grain growth in both steels. Based on (2), the $K$ values obtained at different temperatures when plotted versus $1 / T$ using a semilogarithmic scale can be used to determine $Q$ value. Such plot is presented in Figure 5. The value of $Q$ inferred 


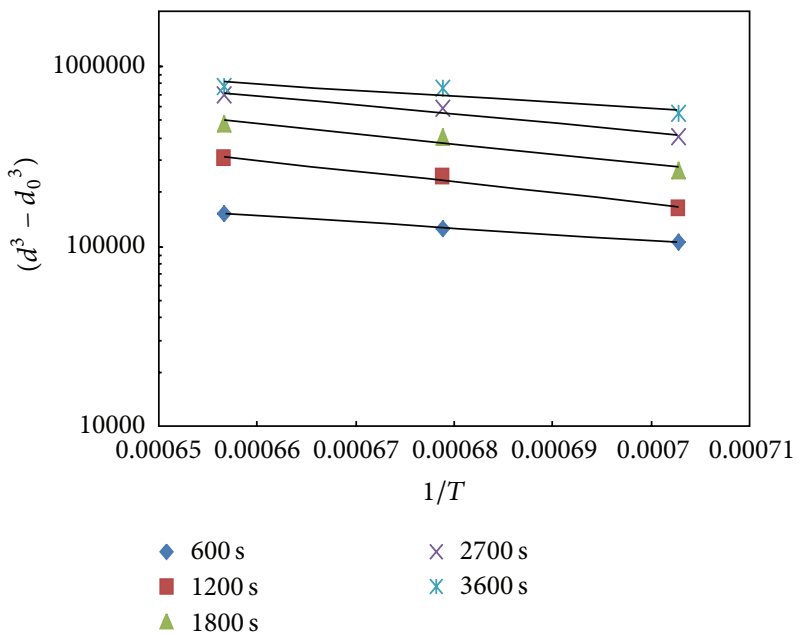

(a)

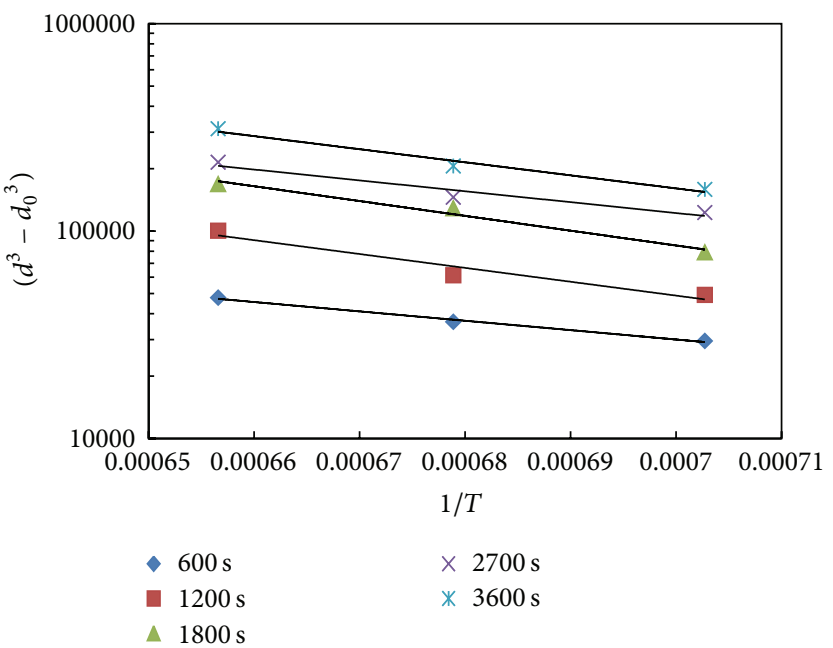

(b)

Figure 6: $\left(d^{3}-d_{0}{ }^{3}\right)$ versus $1 / T$ plot for (a) X65 and (b) X70.

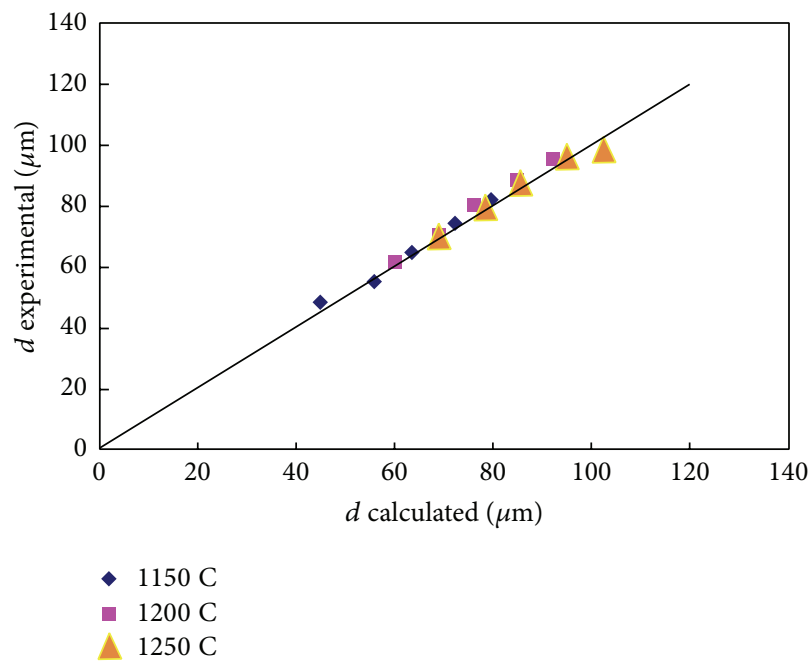

(a)

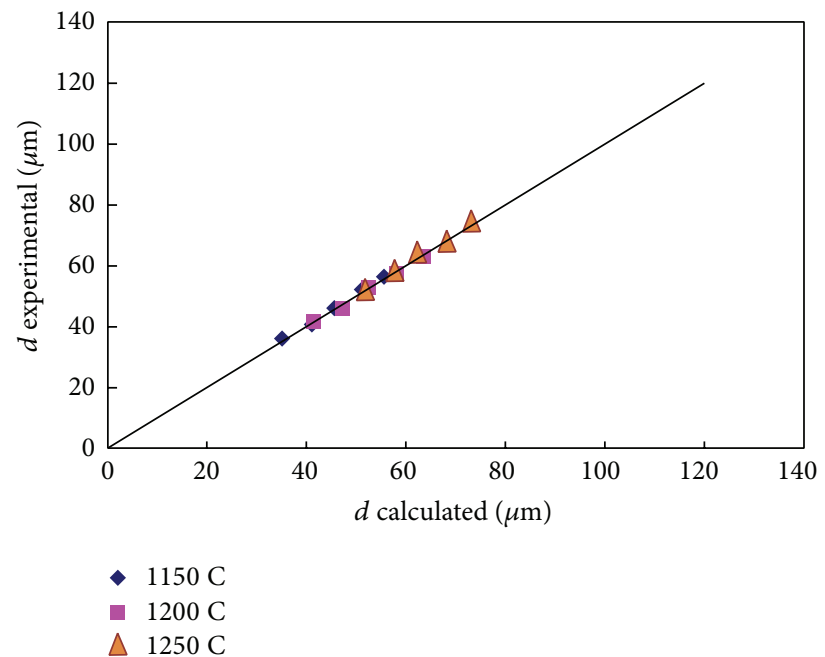

(b)

FIgURE 7: Relation between experimental and calculated grain size values of (a) X65 and (b) X70.

from such a plot is $\sim 100$ and $117 \mathrm{~kJ} / \mathrm{mol}$ for $\mathrm{X} 65$ and $\mathrm{X} 70$, respectively. In addition, (3) can be used to double check the values of $Q$ by plotting $\ln \left(d^{n}-d_{0}{ }^{n}\right)$ versus $1 / T$ at constant time.

At constant time $t$ and $n=3$, the equation $d^{n}-d_{0}{ }^{n}=$ At $\exp (-Q / R T)$ can be rewritten, after taking the natural logarithm of both sides, as

$$
\ln \left(d^{3}-d_{0}^{3}\right)=\ln B-\frac{Q}{R}\left(\frac{1}{T}\right)
$$

where $B$ is a new constant $(B=A t ; t$ is constant).

The values of $\left(d^{3}-d_{0}{ }^{3}\right)$ are plotted against $1 / T$ using semilogarithmic scale in order to find the activation energy, $Q$. The values of $d_{0}{ }^{3}$ were estimated from the best fit of data presented at Figure 4; it is clear that the value of $d_{0}{ }^{3}$ increases with increasing temperature.

The activation energy, $Q$, values were calculated from the slope of the lines from Figures 6(a) and 6(b) for both grades and the average value is 107 and $120 \mathrm{~kJ} / \mathrm{mol}$, for X65 and X70, respectively. These values are in good agreement with those (100 and $117 \mathrm{~kJ} / \mathrm{mol}$, resp.) deduced from Figure 5.

The activation energy for the transfer of atoms across a general grain boundary (grain growth) should be about half that for self-diffusion [19]. The activation energy for iron diffusion in austenite is $286 \mathrm{~kJ} / \mathrm{mol}$ [20] so that the expected $Q$ should be about $143 \mathrm{~kJ} / \mathrm{mol}$. The present values are not too far from the value expected for grain boundary diffusion in austenite. A value of $190 \mathrm{~kJ} / \mathrm{mol}$ was reported for grain growth in microalloyed steel [18]. Higher values were also reported 
for grain growth in other alloy steels $[17,18]$ and the reason for those high values that are higher than that of self-diffusion in austenite is not very well understood. However, it has been demonstrated recently that $Q$ values can be in the range of 69 to $141 \mathrm{~kJ} / \mathrm{mol}$ for a number of low alloy steels [21]. Those results are in good agreement with the present values of $Q$.

The present finding where the grain size and grain coarsening rate in X70 are less than that in X65 is in harmony with the results presented in [11]. It is worth mentioning that $\mathrm{N}$ content in X70 is 0.0064 as compared to 0.005 in X65 and the corresponding Ti content is 0.018 and 0.02 , respectively; see Table 1 . The ratio of $\mathrm{Ti} / \mathrm{N}$ in $\mathrm{X} 70$ is 2.8 , which is less than stoichiometric ratio of 3.4 , which means excess $\mathrm{N}$. This is consistent with the finding in [11] and leads to smaller grain size of austenite and lower coarsening rate in X70 as compared to X65. X65 grade has Ti/N ratio $(0.02 / 0.005=4.0)$ which is more than stoichiometric ratio, that is, less $\mathrm{N}$. This agrees with higher grain size and faster coarsening rate in $\mathrm{X} 65$. The usefulness of overstoichiometric $\mathrm{N}$ contents in $\mathrm{Ti}-$ $\mathrm{V}$ steels for grain size control in the HAZ of welds has been demonstrated [16], as in X70.

In order to correlate the grain size $(d, \mu \mathrm{m})$ values obtained from experiment with the prediction of the model, the values of constant $A$ were calculated by taking $n=3$ and the $Q$ values of 107 and $120 \mathrm{~kJ} / \mathrm{mol}$ for both grades, respectively. The constant $A$ has a value of $1.2 \times 10^{6}$ and $1.1 \times 10^{6}$ for X65 and X70, respectively. It seems that $A$ value is similar in both steels.

Finally, the grain size, $d$, values have been calculated from the obtained values of $n, Q$, and $A$ at different times and temperatures and compared with the experimental $d$ values. The experimental $d$ values are plotted against calculated $d$ values as shown in Figure 7 for both grades.

Figure 7 shows that there is a good agreement between experimental and calculated $d$ values for both grades.

\section{Conclusions}

(1) The grain size increases with increasing reheating temperature and time for both API steels grades X65 and X70.

(2) The austenite grain size (AGS) in X65 steel is larger than that of X70 steel.

(3) Value of $n=3$ is best fitted for grain growth data for both X65 and X70 steel grades.

(4) $Q$ values of 107 and $120 \mathrm{~kJ} / \mathrm{mol}$ are obtained in X65 and X70 grades. These values are not too far from $143 \mathrm{~kJ} / \mathrm{mol}$ for grain boundary diffusion in austenite.

(5) Good agreement is obtained between the prediction of the model and the experimental grain size values using the calculated $A, n$, and $Q$ values.

\section{Conflict of Interests}

The authors declare that there is no conflict of interests regarding the publication of this paper.

\section{Acknowledgments}

This research work was in collaboration with Saudi Basic Industries Company (SABIC) and Center of Excellence for Research in Engineering Materials (CEREM) of Advanced Manufacturing Institute, King Saud University, Riyadh, Saudi Arabia. The CEREM financial support is gratefully acknowledged.

\section{References}

[1] I. A. Yakubtsov, P. Poruks, and J. D. Boyd, "Microstructure and mechanical properties of bainitic low carbon high strength plate steels," Materials Science and Engineering A, vol. 480, no. 1-2, pp. 109-116, 2008.

[2] M.-C. Zhao, K. Yang, and Y.-Y. Shan, "Comparison on strength and toughness behaviors of microalloyed pipeline steels with acicular ferrite and ultrafine ferrite," Materials Letters, vol. 57, no. 9-10, pp. 1496-1500, 2003.

[3] F. Xiao, B. Liao, D. Ren, Y. Shan, and K. Yang, "Acicular ferritic microstructure of a low-carbon $\mathrm{Mn}-\mathrm{Mo}-\mathrm{Nb}$ microalloyed pipeline steel," Materials Characterization, vol. 54, no. 4-5, pp. 305-314, 2005.

[4] B. Hwang and C. G. Lee, "Influence of thermomechanical processing and heat treatments on tensile and Charpy impact properties of B and Cu bearing high-strength low-alloy steels," Materials Science and Engineering A, vol. 527, no. 16-17, pp. 43414346, 2010.

[5] V. A. Guimarães, T. B. Pinto, E. J. Giordano, and I. Ferreira, "Influence of intercritical treatment and micromechanisms of fracture toughness of a steel API 5L X65," First Seminar on Fracture Mechanics, 1995.

[6] L.-N. Duan, J.-M. Wang, Q.-Y. Liu, X.-J. Sun, and J.-C. Cao, "Austenite Grain Growth Behavior of X80 Pipeline Steel in Heating Process," Journal of Iron and Steel Research International, vol. 17, no. 3, pp. 62-66, 2010.

[7] S. S. Kojima, M. A. C. A. Sampaio, and I. S. Bott, "The development of API 5L X80 steel for pipe production by TMCR process," T\&B petroleum, year 5, number 15, 2003.

[8] Q.-Y. Sha, G.-J. Huang, J. Guan, X.-J. Ma, and D.-H. Li, "A new route for identification of precipitates on austenite grain boundary in an Nb-V-Ti microalloyed steel," Journal of Iron and Steel Research International, vol. 18, no. 8, pp. 53-57, 2011.

[9] Q. Sha and Z. Sun, "Grain growth behavior of coarse-grained austenite in a Nb-V-Ti microalloyed steel," Materials Science and Engineering A, vol. 523, no. 1-2, pp. 77-84, 2009.

[10] M. Klein, H. Spindler, A. Luger, R. Rauch, P. Stiaszny, and M. Eigelsberger, "Thermomechanically hot rolled high and ultra high strength steel grades: processing, properties and application," Materials Science Forum, vol. 500-501, pp. 543-550, 2005.

[11] R. Lagneborg, T. Siwecki, S. Zajac, and B. Hutchinson, "Role of vanadium in microalloyed steels," Scandinavian Journal of Metallurgy, vol. 28, no. 5, pp. 186-241, 1999.

[12] K. Banerjee, M. Militzer, M. Perez, and X. Wang, "Nonisothermal austenite grain growth kinetics in a microalloyed x80 linepipe steel," Metallurgical and Materials Transactions A: Physical Metallurgy and Materials Science, vol. 41, no. 12, pp. 3161-3172, 2010.

[13] D. Chakrabarti, Development of bimodal grain structures and their effect on toughness in HSLA steel [Ph.D. thesis], University of Birmingham, 2007. 
[14] T. Araki and M. Enomoto, "Microstructural problems of controlled rolled and cooled very low carbon HSLA steels," in Proceedings of the 2nd International Conference on HSLA Steels: Processing, Properties, and Applications, G. Tither, Ed., p. 95, TMS, Beijing, China, October 1990.

[15] H. Hu and B. B. Rath, "On the time exponent in isothermal grain growth," Metallurgical Transactions, vol. 1, no. 11, pp. 3181-3184, 1970.

[16] J. Moon, J. Lee, and C. Lee, "Prediction for the austenite grain size in the presence of growing particles in the weld HAZ of Ti-microalloyed steel," Materials Science and Engineering A, vol. 459, no. 1-2, pp. 40-46, 2007.

[17] S. Yao, L. Du, X. Liu, and G. Wang, "Isothermal growth kinetics of ultra-fine austenite grains in a Nb-V-Ti microalloyed steel," Journal of Materials Science and Technology, vol. 25, no. 5, pp. 615-618, 2009.

[18] H. Pous-Romero, I. Lonardelli, D. Cogswell, and H. K. D. H. Bhadeshia, "Austenite grain growth in a nuclear pressure vessel steel," Materials Science and Engineering A, vol. 567, pp. 72-79, 2013.

[19] J. W. Christian, Theory of Transformations in Metal and Alloys. Part I, Pergamon Press, Oxford, UK, 3rd edition, 2003.

[20] J. Askill, Tracer Diffusion Data for Metals, Alloys, and Simple Oxides, IFI/Plenum, New York, NY, USA, 1970.

[21] S.-J. Lee and Y.-K. Lee, "Prediction of austenite grain growth during austenitization of low alloy steels," Materials and Design, vol. 29, no. 9, pp. 1840-1844, 2008. 

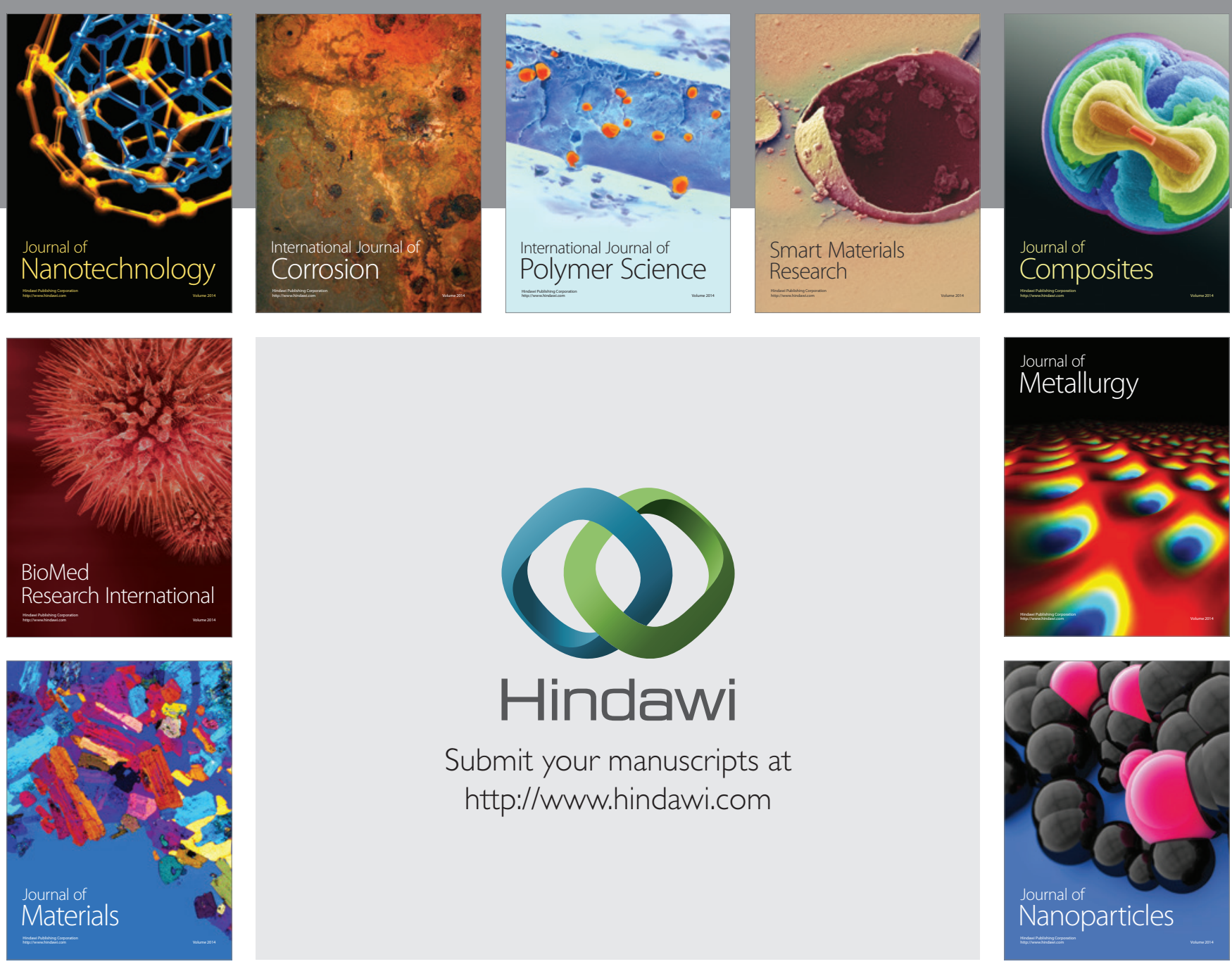

Submit your manuscripts at http://www.hindawi.com
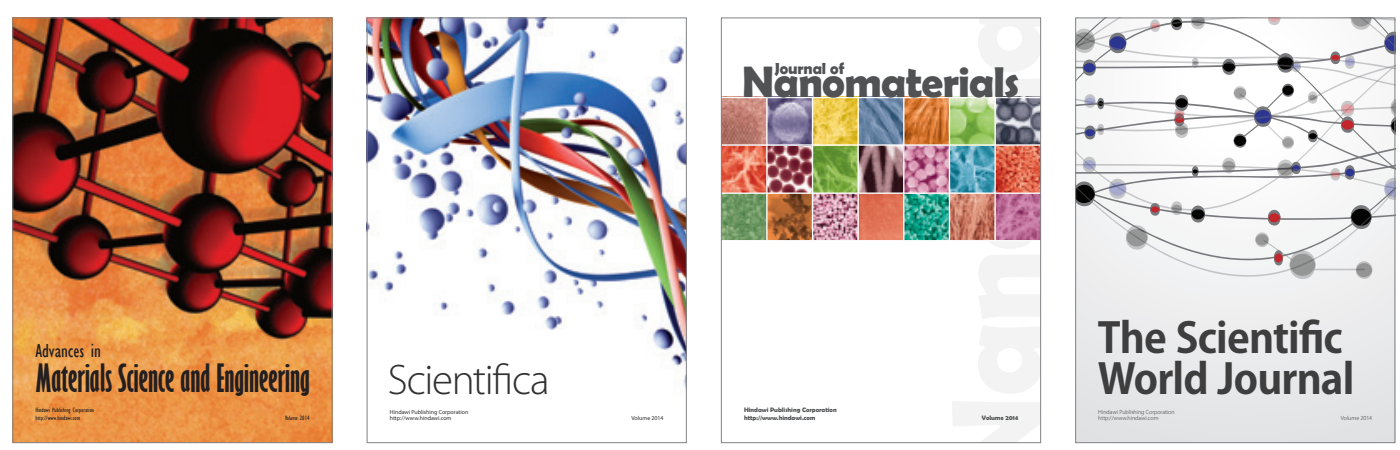

\section{The Scientific World Journal}
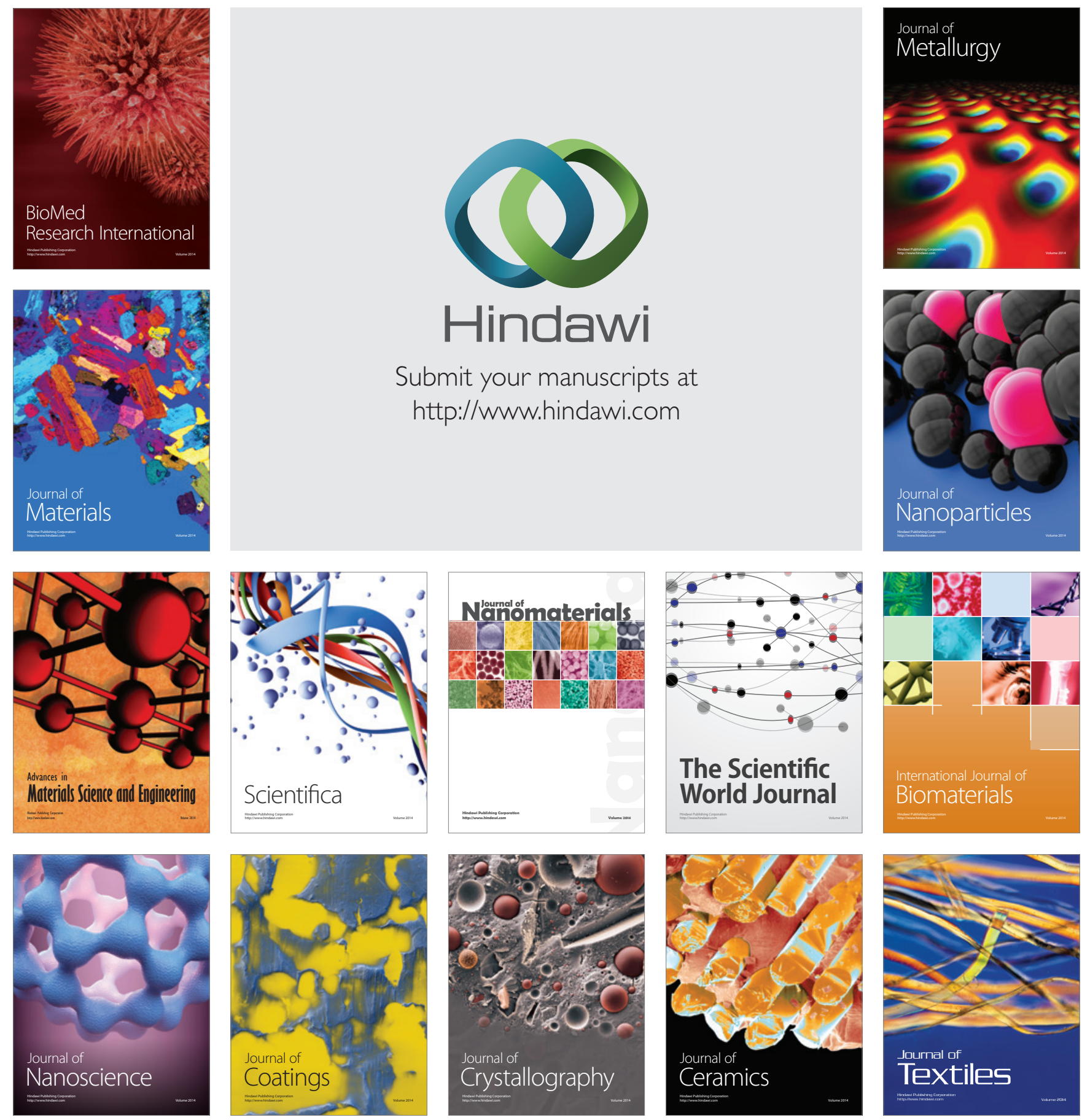